\title{
Electrical Longboard for Everyday Urban Commuting
}

\author{
Alexandru Ciocan ${ }^{1, *}$, Cosmin Ungureanu ${ }^{1,2, *}$, Alin Chitu ${ }^{1}$, Elena Carcadea ${ }^{1}(\mathbb{D}$ and \\ George Darie ${ }^{2}$
}

1 National Research and Development Institute for Cryogenics and Isotopic Technologies-ICSI Rm. Valcea, 4 Uzinei Street, P.O. Box Râureni 7, 240050 Rm. Valcea, Romania; alin.chitu@icsi.ro (A.C.); elena.carcadea@icsi.ro (E.C.)

2 Faculty of Power Engineering, Politehnica University of Bucharest, Splaiul Independenței 313, P.O. 060042 Bucharest, Romania; george.darie@energy.pub.ro

* Correspondence: alexandru.ciocan@icsi.ro (A.C.); cosmin.ungureanu@icsi.ro (C.U.)

Received: 3 September 2020; Accepted: 28 September 2020; Published: 30 September 2020

check for updates

\begin{abstract}
This paper addresses the possibility of using an electric longboard in daily travel. A conventional longboard was transformed into an electric one and tested in ICSI Rm. Valcea labs. A series of tests were performed both at the laboratory level and, under normal running conditions, outdoors. Nevertheless, two possible scenarios have been taken into consideration. First, when the electric longboard is running on a flat road with a cruise speed, while the second scenario considered was that of climbing a hill with a $10 \%$ slope. The results confirmed the expectations and showed that a full charge of the batteries allows a trip over a distance of almost $50 \mathrm{~km}$ on a flat route having a consumption of about $10 \mathrm{Wh} / \mathrm{km}$. However, there are some things to keep in mind when making travel distance predictions. The quality and the profile of the road, the weight of the rider, the rider position, all of these are factors which can significantly influence the predictions regarding the travel distance. Moreover, if the optimization is taken into account, several adjustments can be done in choosing the size and wheel model, whether or not to equip the skateboard with suspensions as well as a compromise between power and energy densities when choosing battery type is essential.
\end{abstract}

Keywords: lithium-ion batteries; energy storage; electric longboard; battery management system

\section{Introduction}

In recent years, the problem of air pollution and increasing emissions of carbon dioxide has represented a real concern for scientific community, decision making factors, and the population. We are going through a transition period and a series of decisions have been taken and must continue with the main objective being to limit global warming. At the EU level, several directives have been required over the years considering the $\mathrm{CO}_{2}$ limitations and renewable energy technology integration into the energy sector mix [1-4]. There are several predicted scenarios regarding the roadmaps for 2050 with an interim target for 2030 and a consensus that a higher contribution of renewable sources is hard to achieve without energy storage solutions. Currently the EU proposes a 1 tn Euro budget through the Green-Deal project which aims to finance industrial sectors in order to reach the proposed goals. An important contribution to pollution from the industrial sector is given by transportation, which represents $25-27 \%$ of global pollution. In recent years, huge progress has been made in this field, as electric vehicles and hydrogen vehicles are being considered as the alternative to the fossil fuel-driven vehicle [3,4]. Neither technologies are mature yet, but the electric vehicle appears to be more affordable than hydrogen vehicles. Research and development activities have accelerated in order to bring advanced energy storage solutions to the market level, with minimal help from support mechanisms. A decrease in battery prices has been seen since 2015 [5-7]. 
Currently, there are three main types of Li-ion cells: cylindrical (with 18650 being the most common standard), pouch, and coin cells having different chemistries, unique properties, and being designed for various applications [6-17]. In the literature, a series of research activities in the field of energy storage are presented [8-12], the lithium batteries being one particular case. Nevertheless, different types of batteries are compared and the autonomy of the life cycle of an electric vehicle is evaluated [7]. Barré et al. [13], Salinas and Kowal [14] and Yi et al. [15] focus their attention on aging mechanisms of Li-ion batteries and algorithms that make the predictions to avoid batteries degradation. A series of key technologies that are correlated with battery modeling, with their state of charge (SOC), state of health $(\mathrm{SOH})$, and the influence of temperature in the use of batteries are presented by Yi et al. [15], Liu et al. [16]. and Zeng et al. [17] refer to reducing energy consumption and the need to use as few resources as possible, highlighting the importance of recycling. Peter et al. [18] evaluate the impact of lithium-ion battery (LIB) in electric vehicle (EV) and made a life cycle assessment, concluding that researchers' efforts should focus not only on maximizing energy density but also on the life cycle and load efficiency. At the same time, Kang et al. [19] present a study in which they classify batteries according to the raw material used and the level of danger.

On the other hand, the car manufacturers have a different approach regarding the type of batteries to be integrated on their vehicles; Tesla used 18650 and later passed to 21700, BMW are using prismatic cells and Nissan Leaf rectangular pouch cells. Regarding battery geometry, most EV markets and suppliers use 18650, but on the other hand the pouch cell market is covered by electronic devices, the most representatives being smartphones and laptops [20]. There are a lot of predictions which say that the number of EV users will increase rapidly; Miao et al. [6] expect 125 million EV by 2030. One of the key elements in batteries' integration in electric vehicles is given by the battery management system. There are studies [21-27] that address the vehicle control unit and the battery management system, presenting new control systems, new hardware in the loop configurations, and evaluating the reliability of an EV system from the perspective of power supply.

Besides mass transportation, another solution for short distance traveling can be represented by individual transport means such as: electric-bikes, scooters, longboards, or hoverboards. All of these can prove to be suitable solutions for commuting to work/school in crowded cities, to explore the neighborhood, or any other trips that do not involve carrying heavy baggage. Ito et al. [12], Muenzel et al. [28] and Yoo et al. [29] investigate the dynamics of the propulsion mechanism of a skateboard using computer simulations based on different lithium-ion battery chemistry. Kuleshov [30,31] followed the linear stability of the skateboard-skater system and develop a model of motion. Hart et al. [32] realized a first attempt of a computational fluid dynamics (CFD) aerodynamic analysis of a downhill skateboard. Varszegi et al. [33] focused their attention on how the balancing effort of the skater influences the stability. Hyvönen et al. [34] conducted a study aimed at seeing how the population of Finland responds to the challenges in the transport system and how they are seeing the use of the light electric vehicle. Studies [35-43] present the most frequent injuries among skateboarders and to which age groups they happen, meanwhile showing the influence of pedestrian crowdedness on light electric vehicle navigation behavior.

When it comes to small electric vehicles, they are expected to have a battery with low weight, compact size, plenty of current delivery for quick acceleration, and high capacity for long-range. It is easy to see that the technology is ever-changing and nearer evident to observe that this is the case in the electronics market. If we are looking back several years ago a few people could imagine this evolution, and today, they are not only thoughts but realities.

Therefore, this study aimed to present the challenges of riding an electric skateboard and makes the following contributions:

(1) On global warming concerns, the paper presents the considerations of using light electric vehicles in everyday travels.

(2) Turns a conventional skateboard into an electric one by integrating a battery stack, a battery cooling system, a battery management system (BMS) and finally testing it. 
(3) Show laboratory testing results for a battery stack discharging by simulating the travel conditions of an electric longboard both on flat ground and for an uphill

(4) Show results from testing the electric longboard functionality in normal driving conditions

The work was structured as follows: the first part introduces the topic, presents and briefly describes the issues addressed in a period of energy transition. In Section 2, Materials and Methods, the electric longboard configuration is presented, the way it was conceived highlighting the characteristics of each component and proposing at the end of the section a mathematical model. Section 3, Results and Discussions, illustrates the results obtained in both laboratory and real-time tests, then are discussed and critically analyzed, with the aim being to evaluate the options and establish strategies to address the issues to improve the system performances. The conclusions are presented in Section 4, and convey the essential outcomes of this paper.

\section{Materials and Methods}

First, when we talk about running a light electric vehicle, in this case an electric longboard, it is important to show the difference between power and energy densities. With double the energy we double the range, but power is that which determines how fast we move. A high-power drive train is useless without a high-power battery, mainly if we refer to the situation when we have to climb a hill. On the other hand, it is also important to have a system that allows a fast-charging battery from a regenerative break during a downhill slope in order to increase the running range.

Thus, to achieve the proposed objective of making an electric longboard it was necessary to carry out several steps. The first step consisted of purchasing a conventional longboard that we proposed to modify into an electric one, therefore we can say that the deck used was a commercial one electrified by us.

The next step was to focus our attention on the battery stack. Due to the fact that any individual cell has limited capacity and voltage, several cells needed to be connected in a package. So, in order to increase the voltage, the cells are connected in series and to increase the capacity/current in parallel. In our case, based on a 18650 nickel-cobalt-aluminum (NCA) battery with $3.6 \mathrm{~V}$ and $3500 \mathrm{mAh}$, a design with 10 batteries connected in series was manufactured first, followed by adding another 3 modules of cells in order to increase the battery capacity, obtaining, at the end, a connection 10S4P, $36 \mathrm{~V}$ rated voltage and 14 Ah capacity. To obtain the battery stack the method chosen to connect the cells was through a metal strip spot welding from each terminal of the battery. The connection between batteries was done through welding it with a nickel band, having a thickness of $0.8 \mathrm{~mm}$ and a width of $2 \mathrm{~mm}$. Any group of 4 batteries connected in parallel was connected to a battery management system (BMS) which is a board that monitors the individual voltage of the cells from the stack, having the main scope to handle the battery charging and balance to keep any battery cells in good health and protect against over-charging or over-discharging.

The third step was to design a metal case with the purpose of being able to take the heat and dissipate it into the environment, therefore playing the role of a cooling system for the battery stack. The battery stack case was designed in SolidWorks and all components were printed on a 3D Printer Ultimaker SS Mat. using polylactic acid which is a thermoplastic/biodegradable material. The used materials have good characteristics of hardness and mechanical strength.

Any electric drive normally consists of a battery module, a motor controller, a motor itself and a running gear. The battery supplies energy to the motor controller which provides a variable voltage output to the motor in order to control the motor speed or torque. The motor converts electrical energy into kinetic energy for moving the vehicle. There are two possibilities for using the propulsion system, some longboards using two driven motors, others using a single powerful motor, and there is a long discussion that takes into consideration the space available and efficiencies during the optimization process. Although every electric longboard can go uphill, different motor specifications limit the potential. When going uphill, an electric longboard needs enough power linked to the driver's weight and gravity simultaneously. In our configuration, we chose for the solution with 2 motors which can 
provide a maximum power of $2400 \mathrm{~W}$, totally, limited by the BMS parameters at $1800 \mathrm{~W}$, this being the maximum power available. Although the power is significant, at this maximum output power our battery stack would be empty in $16 \mathrm{~min}$. However, it is very unlikely that we would reach these values.

The fourth step was to realize the communication part. Most electronic stability control (ESC) solutions are based on the open hardware project called Vedder Electronic Speed Controller (VESC). Therefore, we bought a FLIPSKY Dual FSESC6.6 to make the connection between the battery stack, more precisely between the batteries BMS and the driving motors. The link to the person who is running the longboard is through a handheld remote; fortunately, most of the electric longboards use wireless handheld remote, all controls are giving instant access to every action of acceleration or braking.

Below in Figures 1-4 the battery stack, the connection between the BMS and the battery pack, the battery pack case and the longboard itself are illustrated. At the same time, in Table 1 the representative parameters for the components of the entire system were centralized.

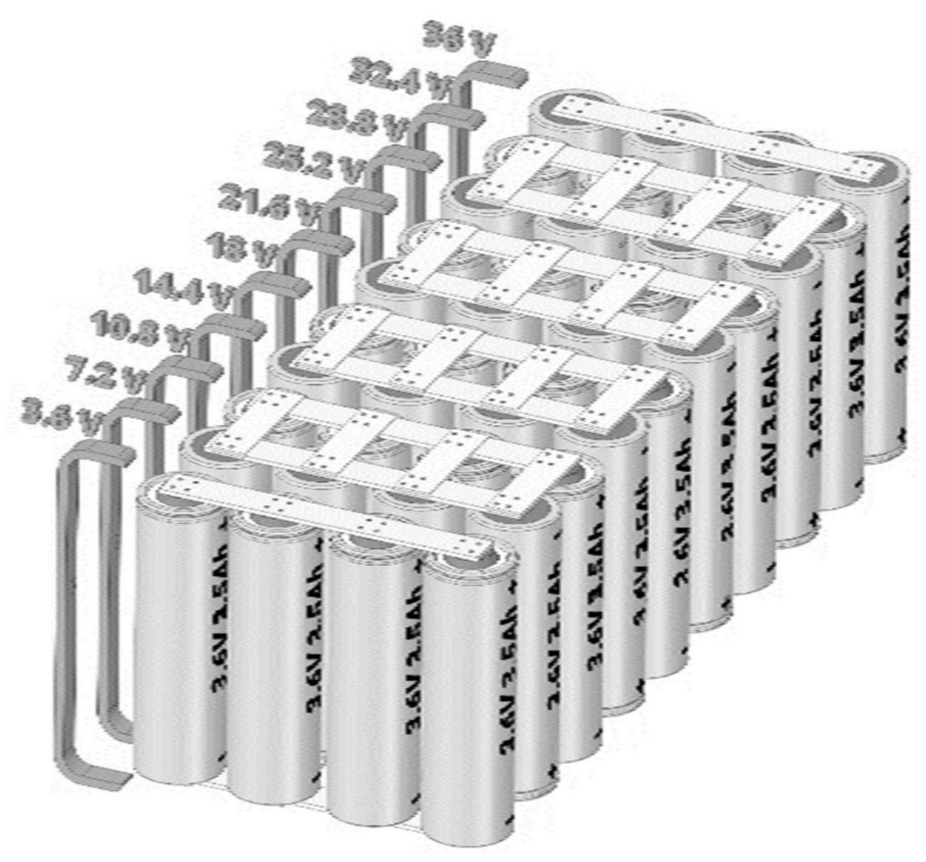

Figure 1. The battery stack.

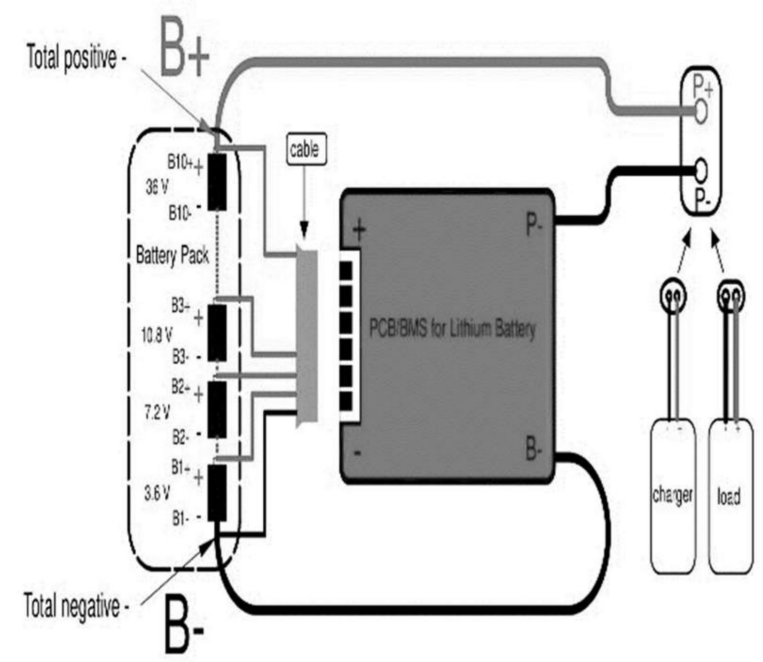

Figure 2. The battery management system (BMS) [adapted by manufacturer datasheet]. 


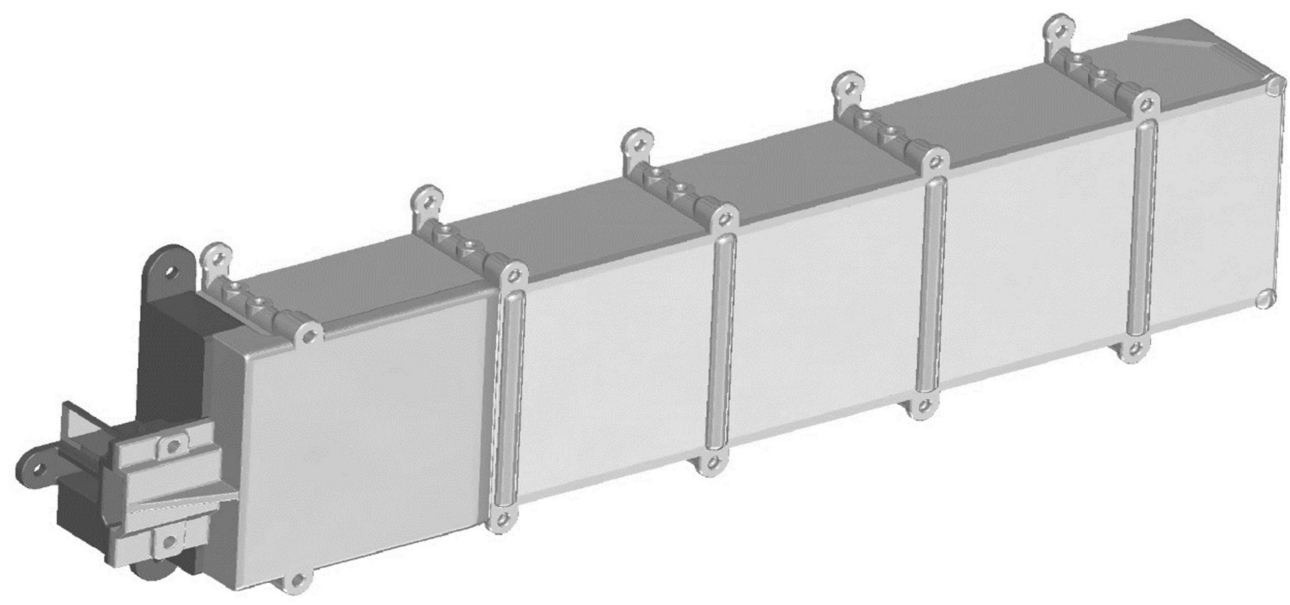

Figure 3. Battery stack case with the role in the cooling process.


Figure 4. Electric longboard prototype.

After assembling all components, the functionality testing was started, therefore a series of parameters was configured, along with a set of limits within which the longboard would be operated. Through VESC application, all the settings required for protecting each component of the longboard had been done, namely: battery with a quick discharge or over discharge, the BMS not to exceed the operating parameters in terms of drawn current, and the motor-controller to provide the motor parameters that are not in its operating range.

The controller used is one which, besides the fact that it allows the user to make the proper configuration, offers the possibility to record a series of parameters which could be seen in real-time through the remote hand controller or on a mobile application that allows the parameters to be downloaded and analyzed later. 
Table 1. Characteristic parameters of a cell battery.

\begin{tabular}{cc}
\hline Battery Chemistry & NCA \\
\hline Capacity & $3.5 \mathrm{Ah}$ \\
Nominal Voltage & $3.6 \mathrm{~V}$ \\
Maximum charging voltage & $4.2 \mathrm{~V}$ \\
\hline Minimum voltage(cut-off) & $2.7 \mathrm{~V}$ \\
Nominal charging current & $2 \mathrm{~A}$ \\
Maximum continue discharging current & $8 \mathrm{~A}$ \\
Discharging current pulse & $13 \mathrm{~A}$ \\
Motor power & $2400 \mathrm{~W}$ \\
Wheel diameter & $83 \mathrm{~mm}$ \\
\hline
\end{tabular}

\section{Theoretical Formulation}

The total mechanical load required to propel an electric longboard is calculated as a sum of the wind resistance, the rolling resistance and the torque required to gain height when it is used to climb a hill. However, there are major losses of resistive power loss in the battery, into the switching controller, hysteresis, and backwash current power losses in the motor.

The force required to overcome the aerodynamic drag is calculated as:

$$
F_{\text {drag }}=1 / 2 \rho A c_{d} v^{2}
$$

The force required to overcome the rolling resistance is calculated as:

$$
F_{\text {roll }}=m g c_{v}
$$

The force required to overcome to gain height when is used to climb a hill, with a given angle of incline, $\theta$, is calculated as:

$$
F_{\text {grav }}=m g \sin (\theta)
$$

The total mechanical load is the sum of all these forces and to convert it into torque we have to multiply it by the radius of the wheel, $r$.

$$
\tau=r\left(F_{\text {drag }}+F_{\text {roll }}+F_{\text {grav }}\right)
$$

Now, the total mechanical power can be calculated as the total mechanical torque multiplied by the angular velocity of the wheel, $w$.

$$
P=\tau w
$$

The angular velocity is calculated as a function of wheel radius, $r$, and linear speed, $v$.

$$
w=v / r
$$

The parameters used in the above equations are: $\rho$-air density, $A$-the front surface of the person on the electric longboard and the longboard itself $\left(0.5-0.6 \mathrm{~m}^{2}\right.$ for a regular person), $c_{d}-$ coefficient of drag (typically 0.25 to 0.4 ), $m$ - the person on the longboard's mass, $g$-gravitational acceleration, $c_{v}$-coefficient of rolling resistance (typically 0.008 to 0.03 ). All the other parameters have been already explained.

Passing from the mechanical power of the motor to the electrical power of the battery stack, the latter is calculated as:

$$
P=U I \text { or } P=R I^{2}
$$

where $U, I$, and $R$ are the battery stack voltage, current and internal resistance. And finally, the energy consumed is calculated by multiplying the power required with the drawing time.

$$
E=P t
$$




\section{Results and Discussions}

The experimental concept of this paper aimed at two results: first, to obtain laboratory results by discharging the batteries on testing equipment, and second to validate these results by testing the electric longboard under normal operating conditions. Using the mathematical model presented above and performing the calculations, the functional parameters have been chosen in order to discharge the battery stack. Since some parameters of the battery stack exceeded the range of the equipment available, a compromise has been made, namely doing the tests at the cell level and making all the necessary similarities required reported at the battery stack level. Therefore, Figures 5 and 6 illustrate the parameters' evolution in time: current, voltage, power, energy and capacity for the scenario in which we are going on a flat route, respectively Figures 7 and 8 took into consideration the scenario in which a $10 \%$ slope is continuously climbed. The assumption which has been done during laboratory tests was that the running speed is maintained constant throughout the trip, this parameter being the one which makes the connection with the power required to train the longboard. As a conclusion the discharge of the batteries is done at constant power.

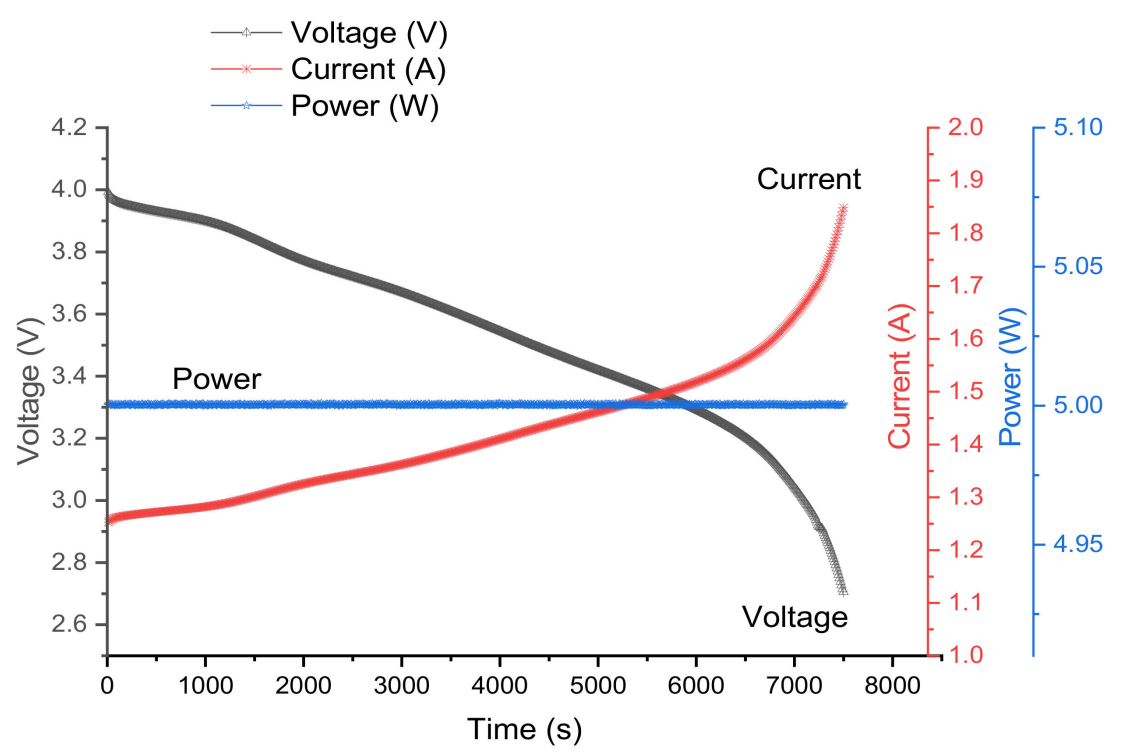

Figure 5. Voltage and current for an electric longboard when it moves on flat ground.

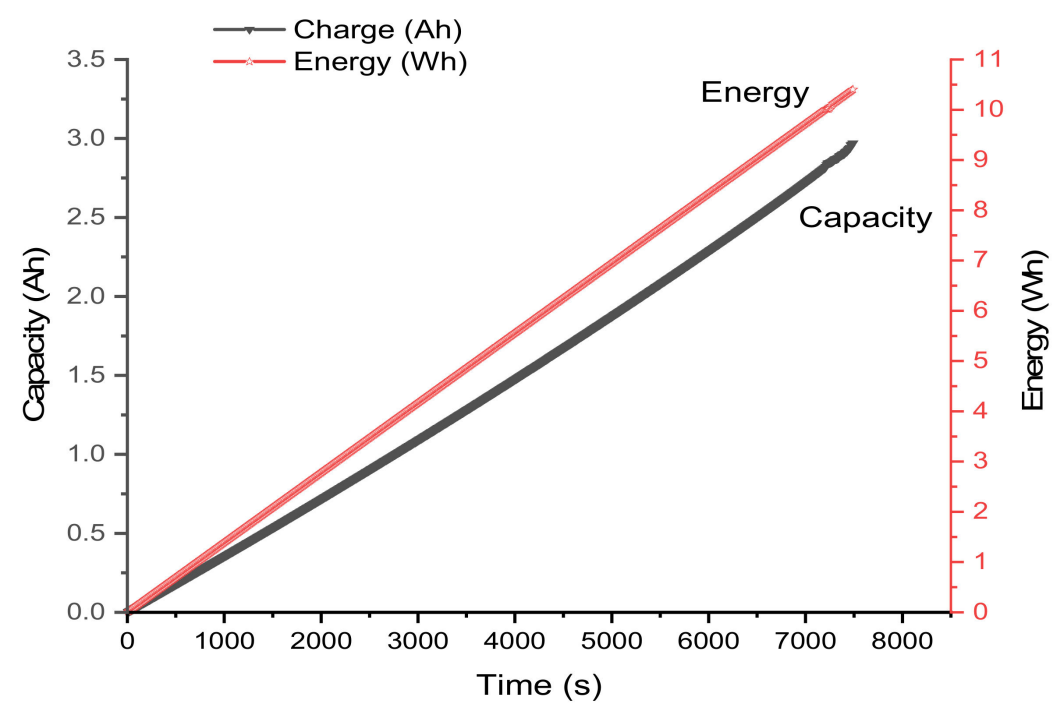

Figure 6. The battery capacity and energy consumed for an electric longboard when it moves on flat ground. 


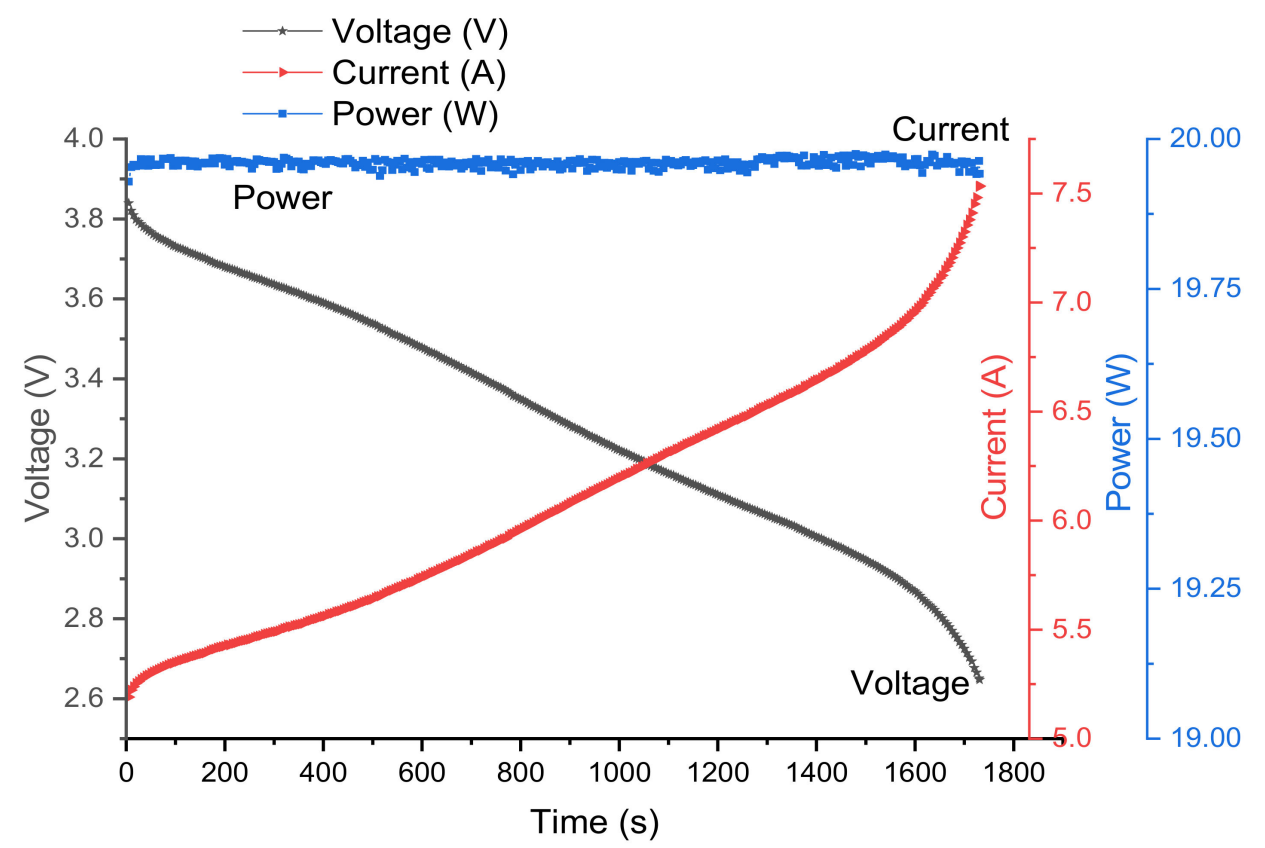

Figure 7. Power, voltage, and current evolution in time for an electric longboard when it climbs a hill.



Figure 8. The battery capacity and energy consumed for an electric longboard when it climbs a hill.

Moving forward, once the simulated results gave us an idea about the functionality of the electric longboard, we moved on to the experimental part, namely the collection of operating parameters in dynamics. A route that was mapped as $90 \%$ flat with a few gentle ascents and descents, which should not have a significant impact on the data was chosen. It is worth mentioning that all the parameters recorded were thorough VESC application at the level of milliseconds, a fact which required complex data processing. Figure 9 illustrates three screenshots, highlighting the operational parameters at a certain point of time. If the two first captures are focused on a cruise scenario on a flat train, the third capture is highlighting the function ability for uphill conditions. The values of current from round dials are for the motor current which is different from the current drawn from the battery. The duty cycle parameter is responsible for this, but only when the duty cycle is $100 \%$ of the current drown from the batteries and the ones that power the motor are equal. 


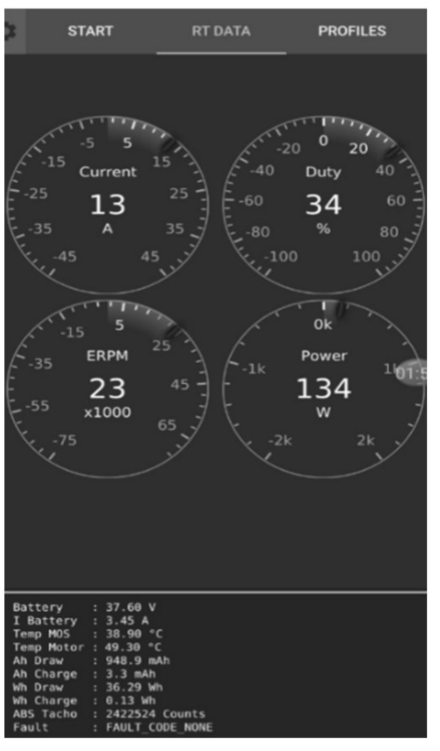

(a)

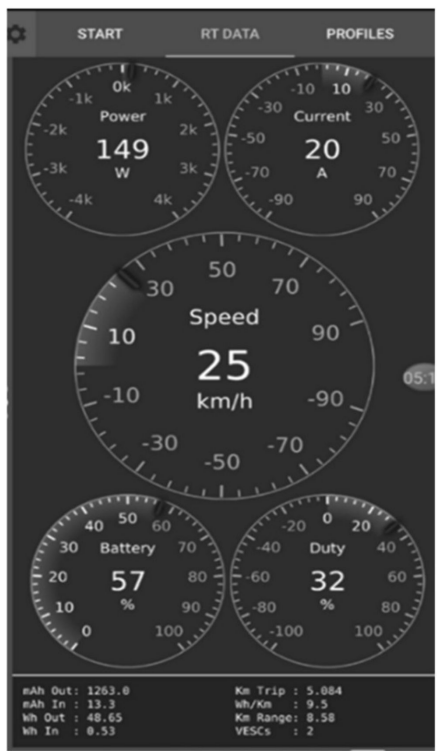

(b)

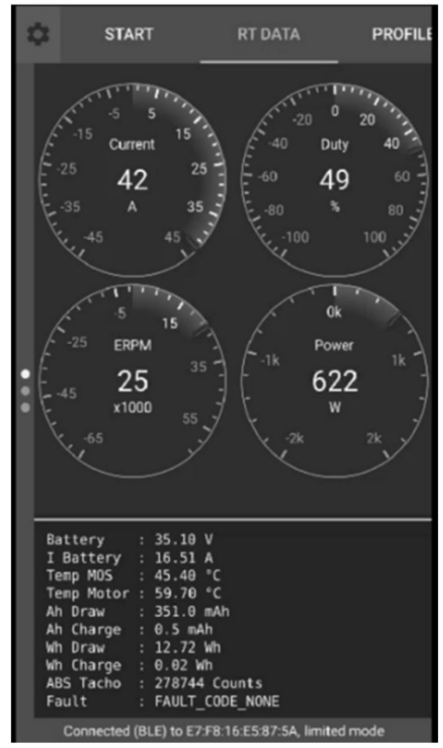

(c)

Figure 9. Vedder Electronic Speed Controller (VESC) Android application illustrating the parameter values at a certain moment of time during the ride, (a) and (b) running flat route and (c) climbing a hill with a $10 \%$ slope.

Figures 10 and 11 show the evolution in time of voltage drawn from the batteries, SOC once the battery is discharged, the speed at which the longboard runs and the power required to run the longboard. Due to the fact that there are too many values spread over a large range because of a much too short data collection interval, two histogram graphs were represented in Figure 12, for speed, and Figure 13, for power, for a better understanding. As an order of magnitude, it can be mentioned that for a flat road the power required was somewhere near $200 \mathrm{~W}$, and in the uphill scenario, 10\% slope, this value increased up to 3.2 times when the skater weight is $75 \mathrm{~kg}$ Another important aspect that had been noticed when climbing a slope was the appearance of the sliding phenomenon, therefore even though there is enough power, there isn't enough torque which leads us to the conclusion that bigger wheels are required for such cases.

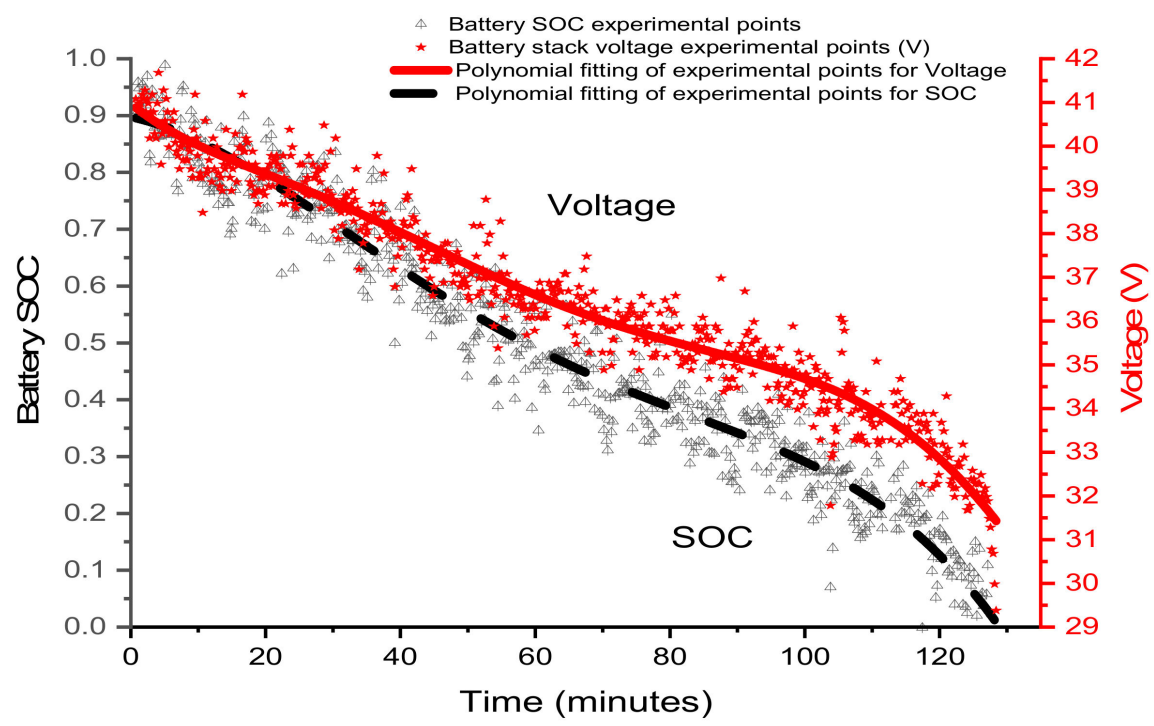

Figure 10. The battery voltage and state of charge (SOC) for an electric longboard when it moves on flat ground. 




Figure 11. The battery power and speed for an electric longboard when it moves on flat ground.

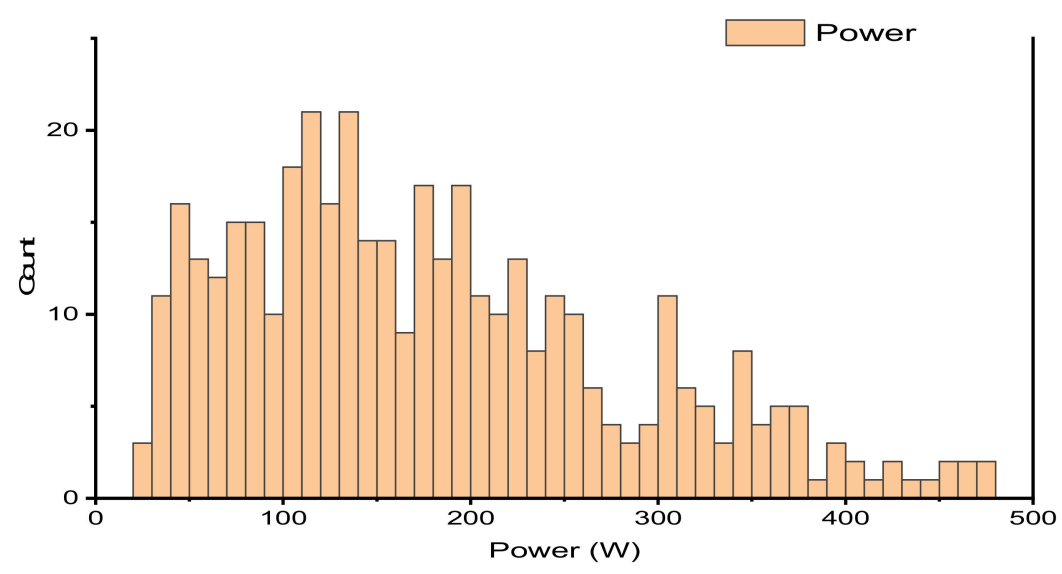

Figure 12. Histogram power representation.

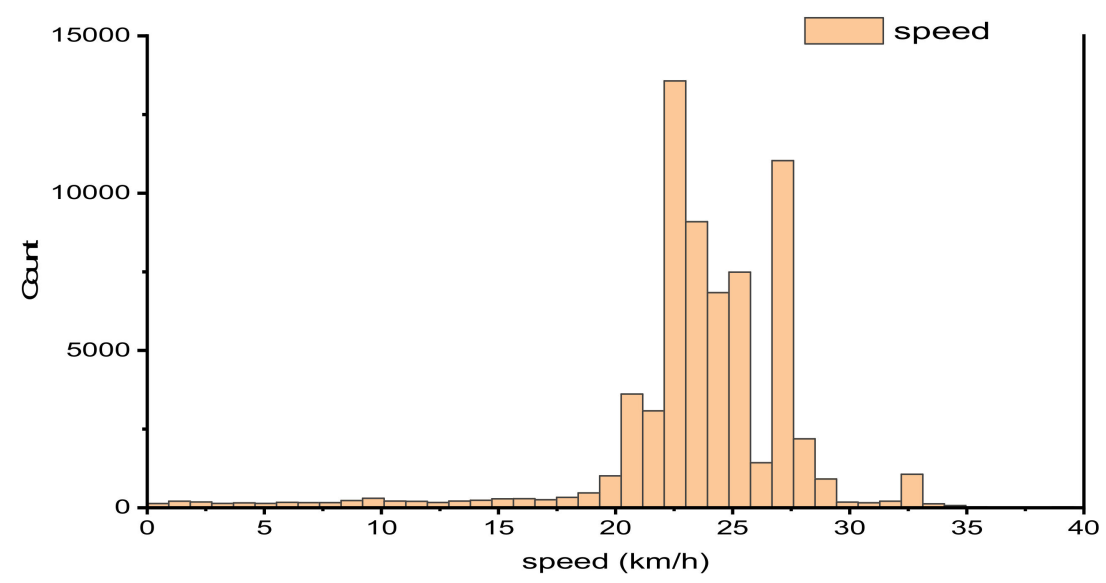

Figure 13. Histogram speed representation.

On the other hand, Figure 14 shows the amount of energy drawn from the battery and the energy recharged due to regenerative breaking. In the motion control industry, the term of regenerative braking refers to using the power associated with the back electromotive force voltage of an electric motor to charge a battery. In fact, this is the opposite of the normal operational mode where the battery is used to provide power to an electric motor. As long as an electric motor can fulfill the role of a generator, 
a system can be designed in such way that the power flow is in or out of the motor and the battery can be charged or discharged in real-time. So, instead of throwing away the back electromotive force power into heat loss, it can be used to recharge the battery, thereby recovering energy, adding to overall system efficiency. In our case, the proportion between energy recharged and energy consumption is $2.5 \%$.

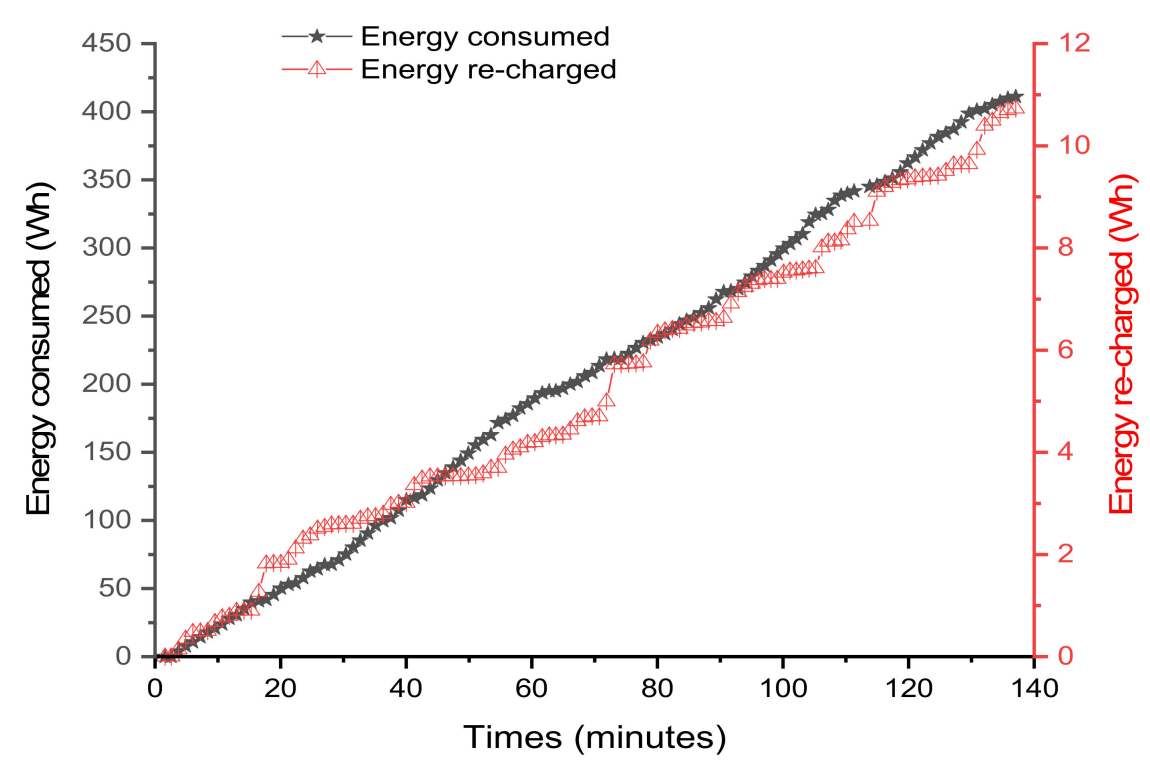

Figure 14. The energy consumption and the energy recharged during a trip.

Figure 15 presents the influence of skater's weight on the power required for running the longboard on flat ground. Therefore, it can be seen that the skater's weight has a major impact on the distance he can travel. Once the experimental results showed the values for the case with a skater whose weight is $75 \mathrm{~kg}$, then simulations were made for other weights. The results showed that by reducing the skater's weight by one third, the distance traveled almost doubles.

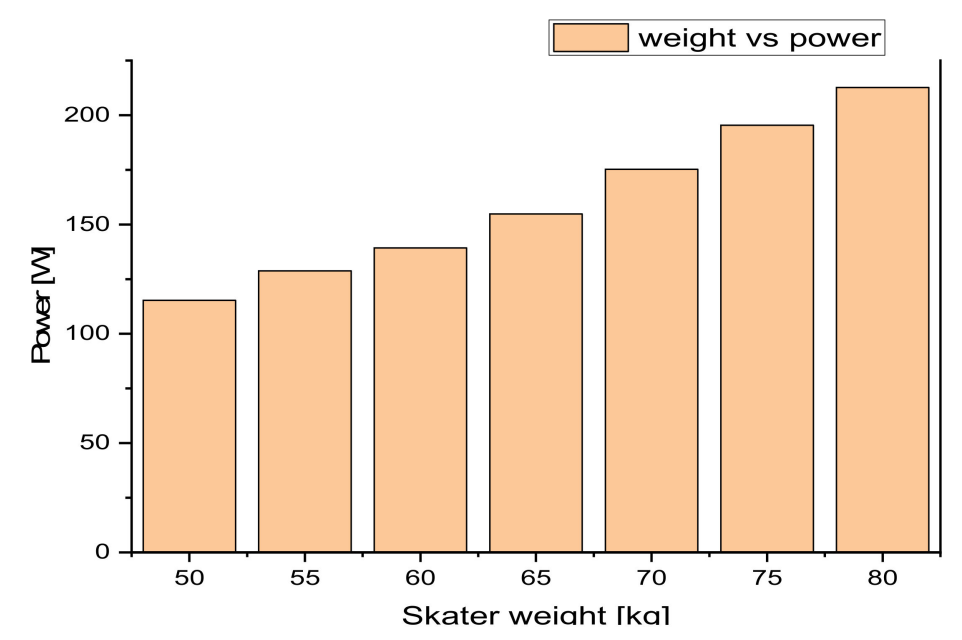

Figure 15. The influence of skater mass on the power required for moving on flat ground.

\section{Conclusions}

Notable achievements have been made during the years, mainly in longevity and safety, while the capacity is gradually increased. Today, Li-ion meets the expectations of most consumer devices, but if we focus our attention on the applications of electric vehicles, then further development is required before this power source will become the accepted norm. 
The advantages that an electric longboard offers refers the easy method of transportation, including for teenagers, to the fact that the lithium battery lasts longer and recharges more quickly than many others and can reach relatively high speeds, having at the same time the disadvantage that the time of use strongly depends on the driver's weight and the piloting style.

In this paper a stack of batteries has been tested, taking into consideration the effect of discharging, capacity, and temperature. The experiments have been done both for components using laboratory equipment and for the entire system by testing it under normal outdoor driving conditions. The results showed no significant differences if we take the scenario of a flat terrain with cruising speed. However, even if, from a theoretical point of view, the power provided by the batteries was still enough, the adjustment inside the controller and implicitly into the motors makes this different from the theoretical expectations. Practically, without a sufficient start, a ramp with an inclination of over $10 \%$ and a length of over $100 \mathrm{~m}$ is difficult to climb, and the more we climb the slope, given by the state of charge of the battery, the more they are charged, and the more we advance.

In terms of energy consumption, there are many factors which influence the consumption, among them being: piloting style, skater weigh, wheel size, road conditions, and in our case, choosing to travel in cruise mode. The experimental results for a $75 \mathrm{~kg}$ skater weight was $9.4 \mathrm{Wh} / \mathrm{km}$, on the other hand the simulation results showed that the consumption can be considerably reduced with the weight loss of the skater. Even the literature reports a large range of this values, from $7.5 \mathrm{Wh} / \mathrm{km}$ to more than $30 \mathrm{Wh} / \mathrm{km}$ without making the link to the weight of the person which is riding the longboard.

Considering the results obtained, an electric longboard could be a means of transportation between the home and work place, or to recreation areas for the days when the weather conditions allow this.

However, even if an electric longboard is charged relatively fast, can travel long distances and reach high speeds, some abilities are required to be able to run it safely, even with the regulatory speed according to the valid legislation in force in most European countries of $25 \mathrm{~km} / \mathrm{h}$.

Author Contributions: Conceptualization, A.C. (Alexandru Ciocan) and A.C. (Alin Chitu); methodology, A.C. (Alexandru Ciocan); software, A.C. (Alin Chitu) and E.C.; validation, A.C. (Alexandru Ciocan) and C.U.; formal analysis, A.C. (Alexandru Ciocan) and C.U.; investigation, A.C. (Alexandru Ciocan) and C.U.; resources, A.C. (Alexandru Ciocan) and C.U.; data curation, A.C. (Alexandru Ciocan) and C.U.; writing-original draft preparation, A.C. (Alexandru Ciocan); writing-review and editing, A.C. (Alexandru Ciocan); visualization, A.C. (Alexandru Ciocan); supervision, E.C. and G.D.; project administration, E.C. and G.D.; funding acquisition, E.C. All authors have read and agreed to the published version of the manuscript.

Funding: This work is supported by the Ministry of Research and Innovation from Romania by the National Plan of R\&D, Project No. PN 19110103 and the publication costs are supported by Politehnica University of Bucharest through "PubArt" program.

Acknowledgments: Research on this paper was supported by the National Research and Development Institute for Cryogenics and Isotopic Technologies-ICSI Rm. Valcea in collaboration with Politehnica University of Bucharest under the guidance of George Darie.

Conflicts of Interest: The authors declare no conflict of interest.

\section{References}

1. EEA-European Environment Agency. Emissions of Air Pollutants from Transport. Available online: https://www.eea.europa.eu/data-and-maps/indicators/transport-emissions-of-air-pollutants-8/transportemissions-of-air-pollutants-8 (accessed on 27 February 2020).

2. Anenberg, S.; Miller, J.; Henze, D.; Minjares, R. A Global Snapshot of the Air Pollution-Related Health Impacts of Transportation Sector Emissions in 2010 and 2015. Available online: https:/theicct.org/sites/ default/files/publications/Global_health_impacts_transport_emissions_2010-2015_20190226.pdf (accessed on 28 May 2020).

3. Eurostat/EC-Greenhouse Gas Emission Statistics-Emission Inventories. 2019. Available online: https://ec. europa.eu/eurostat/statistics-explained/pdfscache/1180.pdf (accessed on 4 March 2020).

4. EPA-United States Environmental Protection Agency. Sources of Greenhouse Gas Emissions. Available online: https://www.epa.gov/ghgemissions/sources-greenhouse-gas-emissions (accessed on 4 March 2020). 
5. BloombergNEF-A Behind the Scenes Take on Lithium-ion Battery Prices. Available online: https://about. bnef.com/blog/behind-scenes-take-lithium-ion-battery-prices (accessed on 2 June 2020).

6. Miao, Y.; Hynan, P.; Von Jouanne, A.; Yokochi, A. Current Li-Ion battery technologies in electric vehicles and opportunities for advancements. Energies 2019, 12, 1074. [CrossRef]

7. Iclodean, C.; Varga, B.; Burnete, N.; Cimerdean, D.; Jurchiş, B. Comparison of Different Battery Types for Electric Vehicles. IOP Conf. Series: Mater. Sci. Eng. 2017, 252, 012058. [CrossRef]

8. Gallo, A.; Simões-Moreira, J.R.; Costa, H.; Santos, M.; Dos Santos, E.M. Energy storage in the energy transition context: A technology review. Renew. Sustain. Energy Rev. 2016, 65, 800-822. [CrossRef]

9. Luo, X.; Wang, J.; Dooner, M.; Clarke, J. Overview of current development in electrical energy storage technologies and the application potential in power system operation. Appl. Energy 2015, 137, 511-536. [CrossRef]

10. Guney, M.S.; Tepe, Y. Classification and assessment of energy storage systems. Renew. Sustain. Energy Rev. 2017, 75, 1187-1197. [CrossRef]

11. Światowska, J.; Barboux, P. Chapter 4-Lithium battery technologies: From the electrodes to the batteries. In Resources, Extraction Batteries and Recycling; Lithium Process Chemistry; Elsevier: Amsterdam, The Netherlands, 2015; pp. 125-166.

12. Ito, S.; Takeuchi, S.; Sasaki, M. Motion measurement of a two-wheeled skateboard and its dynamical simulation. Appl. Math. Model. 2012, 36, 2178-2191. [CrossRef]

13. Barré, A.; Deguilhem, B.; Grolleau, S.; Gerard, M.; Suard, F.; Riu, D. A review on lithium-ion battery ageing mechanisms and estimations for automotive applications. J. Power Sources 2013, 241, 680-689. [CrossRef]

14. Salinas, F.; Kowal, J. Classifying Aged Li-Ion Cells from Notebook Batteries. Sustainability 2020, $12,3620$. [CrossRef]

15. Yi, J.; Kim, U.S.; Shin, C.B.; Han, T.; Park, S. Modeling the temperature dependence of the discharge behavior of a lithium-ion battery in low environmental temperature. J. Power Sources 2013, 244, 143-148. [CrossRef]

16. Liu, K.; Li, K.; Peng, Q.; Zhang, C. A brief review on key technologies in the battery management system of electric vehicles. Front. Mech. Eng. 2018, 14, 47-64. [CrossRef]

17. Zeng, X.; Li, J.; Singh, N. recycling of spent lithium-ion battery: A critical review. Crit. Rev. Environ. Sci. Technol. 2014, 44, 1129-1165. [CrossRef]

18. Peters, J.F.; Baumann, M.; Zimmermann, B.; Braun, J.; Weil, M. The environmental impact of Li-Ion batteries and the role of key parameters-A review. Renew. Sustain. Energy Rev. 2017, 67, 491-506. [CrossRef]

19. Kang, D.H.P.; Chen, M.; Ogunseitan, O.A. Potential environmental and human health impacts of rechargeable lithium batteries in electronic waste. Environ. Sci. Technol. 2013, 47, 5495-5503. [CrossRef]

20. Kayyar, A.; Huang, J.; Samiee, M.; Luo, J. Construction and testing of coin cells of lithium ion batteries. J. Vis. Exp. 2012, e4104. [CrossRef]

21. Ricco, M.; Meng, J.; Gherman, T.; Grandi, G.; Teodorescu, R. Smart battery pack for electric vehicles based on active balancing with wireless communication feedback. Energies 2019, 12, 3862. [CrossRef]

22. Kumar, M.S.; Revankar, S.T. Development scheme and key technology of an electric vehicle: An overview. Renew. Sustain. Energy Rev. 2017, 70, 1266-1285. [CrossRef]

23. Burs, L.; Roemer, E.; Worm, S.; Masini, A. Are they all equal? Uncovering adopter groups of battery electric vehicles. Sustainability 2020, 12, 2815. [CrossRef]

24. Dai, H.; Zhang, X.; Wei, X.; Sun, Z.; Wang, J.; Hu, F. Cell-BMS validation with a hardware-in-the-loop simulation of lithium-ion battery cells for electric vehicles. Int. J. Electr. Power Energy Syst. 2013, 52, 174-184. [CrossRef]

25. Shu, X.; Yang, W.-X.; Guo, Y.; Wei, K.; Qin, B.; Zhu, G. A reliability study of electric vehicle battery from the perspective of power supply system. J. Power Sources 2020, 451, 227805. [CrossRef]

26. Guoning, X.; Du, X.; Li, Z.; Zhang, X.; Zheng, M.; Miao, Y.; Gao, Y.; Liu, Q. Reliability design of battery management system for power battery. Microelectron. Reliab. 2018, 88-90, 1286-1292. [CrossRef]

27. Yunzheng, Z.; Shaofei, Q.; Huang, A.C.; Jianhong, X. Smart vehicle control unit-an integrated BMS and VCU system. IFAC-PapersOnLine 2018, 51, 676-679. [CrossRef]

28. Muenzel, V.; Hollenkamp, A.F.; Bhatt, A.I.; De Hoog, J.; Brazil, M.; Thomas, D.A.; Mareels, I.A. Comparative testing study of commercial 18650-format lithium-ion battery cells. J. Electrochem. Soc. 2015, 162, 1592-1600. [CrossRef] 
29. Yoo, G.-W.; Jang, B.-C.; Son, J.-T. Novel design of core shell structure by NCA modification on NCM cathode material to enhance capacity and cycle life for lithium secondary battery. Ceram. Int. 2015, 41, 1913-1916. [CrossRef]

30. Kuleshov, A.S. Nonlinear analysis of the skateboard dynamics. In Proceedings of the XXI ISB Congress of International Society of Biomechanics, Taipei, Taiwan, 1-5 July 2007.

31. Kuleshov, A.S. Various schemes of the skateboard control. Procedia Eng. 2010, 2, 3343-3348. [CrossRef]

32. Hart, J.; Allen, T.; Holroyd, M. Downhill skateboard aerodynamics. Procedia Eng. 2010, 2, $2523-2528$. [CrossRef]

33. Várszegi, B.; Takács, D.; Stepan, G. Position control of rolling skateboard. IFAC-PapersOnLine 2015, 48, 286-291. [CrossRef]

34. Hyvönen, K.; Repo, P.; Lammi, M. Light Electric vehicles: Substitution and future uses. Transp. Res. Procedia 2016, 19, 258-268. [CrossRef]

35. Kazemzadeh, K.; Laureshyn, A.; Ronchi, E.; Dágostino, C.; Hiselius, L.W. Electric bike navigation behaviour in pedestrian crowds. Travel Behav. Soc. 2020, 20, 114-121. [CrossRef]

36. Johnson, M.; Rose, G.; Rose, G. Extending life on the bike: Electric bike use by older Australians. J. Transp. Heal. 2015, 2, 276-283. [CrossRef]

37. Siman-Tov, M.; Radomislensky, I.; Peleg, K.; Bahouth, H.; Becker, A.; Jeroukhimov, I.; Karawani, I.; Kessel, B.; Klein, Y.; Lin, G.; et al. A look at electric bike casualties: Do they differ from the mechanical bicycle? J. Transp. Heal. 2018, 11, 176-182. [CrossRef]

38. Ji, S.; Cherry, C.; Han, L.D.; Jordan, D.A. Electric bike sharing: Simulation of user demand and system availability. J. Clean. Prod. 2014, 85, 250-257. [CrossRef]

39. Lustenberger, T.; Talving, P.; Barmparas, G.; Schnüriger, B.; Lam, L.; Inaba, K.; Demetriades, D. Skateboard-related injuries: Not to be taken lightly. A National Trauma Databank Analysis. J. Trauma: Inj. Infect. Crit. Care 2010, 69, 924-927. [CrossRef] [PubMed]

40. Keilani, M.; Krall, C.; Lipowec, L.; Posch, M.; Komanadj, T.S.; Crevenna, R. Skateboarding Injuries in Vienna: Location, frequency, and severity. PMER 2010, 2, 619-624. [CrossRef]

41. Kyle, S.B.; Nance, M.L.; Rutherford, G.W.; Winston, F.K. Skateboard-Associated Injuries: Participation-Based Estimates and Injury Characteristics. J. Trauma: Inj. Infect. Crit. Care 2002, 53, 686-690. [CrossRef]

42. Keays, G.; Dumas, A. Longboard and skateboard injuries. Injury 2014, 45, 1215-1219. [CrossRef]

43. Tominaga, G.T.; Schaffer, K.B.; Dandan, I.S.; Kraus, J. Epidemiological and clinical features of an older high-risk population of skateboarders. Injury 2013, 44, 645-649. [CrossRef] 